\title{
Transposon Silencing and Imprint Establishment in Mammalian Germ Cells
}

\author{
T.H. Bestor AND D. Bourc'HIS \\ Department of Genetics and Development, College of Physicians and Surgeons of Columbia University,
} New York, New York 10032

Activators and repressors cannot explain the regulation of all genes. Some mammalian genes are not expressed even in the presence of all the required transcription factors, and the behavior of these genes also fails to conform to Mendelian laws of transmission genetics. Such genes are said to be under epigenetic control or to be subject to gene silencing. Mammalian gene silencing is especially conspicuous at genes subject to X-chromosome inactivation, at imprinted genes, and at the large number of transposable elements that contain promoter sequences (Bestor 2003). Genes on the inactive $\mathrm{X}$ chromosome are clearly in the presence of all factors required for their expression, as shown by the activity of the homologous alleles on the active $X$, but they remain silent for very long periods of time. The same is true of imprinted genes. The state of activity of a gene subject to X-inactivation or genomic imprinting can be predicted only if the history of the gene is known; in the case of X-inactivation, the critical event occurs in somatic cells soon after implantation, while the state of activity of imprinted genes is determined during spermatogenesis and oogenesis in the previous generation. The promoters of retroposons are silenced in premeiotic prospermatogonia in males and meiotic dictyate oocytes in females. Once established, the silent state can persist for the life of the organism, which in humans can exceed 100 years, and can only be reset in the next reproductive cycle.

Epigenetic gene silencing is unlikely to depend on inheritance of patterns of histone modifications. Histone modifications have not been shown to be heritable and there is no plausible mechanism that might allow heritability. As Henikoff et al. (2004) have noted, histone replacement (especially replacement of histone $\mathrm{H} 3$ by $\mathrm{H} 3.3$ and of histone H2A by H2A.Z) can provide some stability to chromatin states, but dilution by $\mathrm{S}$ phase histones in cycling cells will obviate true heritability. Ongoing transcription is required to maintain high levels of H3.3 and H2A.Z in dividing cells. This clearly cannot explain genomic imprinting at the $H 19$ locus, where a decision is taken to irreversibly inactivate $\mathrm{H} 19$ within a few days of birth and the restricted expression potential maintained for decades in the absence of H19 expression. Allele-specific $H 19$ expression is only realized in offspring that can be separated by decades and by more than 50 mitotic divisions from the event that restricted the potential of the $H 19$ gene. No plausible mechanism by which histone modification could mediate such an effect has been put forward (for review, see Goll and Bestor 2002), even though it is widely assumed that histone modifications mediate all epigenetic effects.

The heritability of cytosine methylation and the inactivation of promoters by methylation have been confirmed in many experiments over the last 25 years (for an especially convincing recent example, see Lorincz et al. 2002). Nearly all available data indicate that epigenetic effects in mammals depend largely on heritable genomic methylation patterns. Demethylation of the genome causes the loss of most genomic imprinting, the inactivation of all $\mathrm{X}$ chromosomes by reactivation of Xist, and the fulminating expression of endogenous retroviruses (for review, see Bestor 2000). However, almost nothing is known of the mechanisms that target specific sequences for de novo methylation. This is true in large part because most de novo methylation takes place in germ cells and early embryos, which have been much less studied than adult tissues, where genomic methylation patterns are more static. DNA methyltransferase 3-like (Dnmt3L; Aapola et al. $2000)$ is a noncatalytic regulatory factor expressed specifically in germ cells, and genetic studies of this factor have begun to reveal the roles of genomic methylation patterns in the germ lines of both males and females.

\section{THE DNA METHYLTRANSFERASES OF MAMMALS}

There are five mammalian proteins that share sequence relatedness with the DNA cytosine-5 methyltransferases of other organisms (Fig. 1), but only three (Dnmt1, Dnmt3A, and Dnmt3B) have been shown to be active transmethylases in both biochemical and genetic tests; Dnmt3L has no in vitro activity but by genetic tests is required for de novo methylation specifically in germ cells, as will be described later. Dnmt2 has shown no evidence of DNA methyltransferase activity in biochemical or genetic assays.

None of the active DNA methyltransferases has inherent sequence specificity beyond the $\mathrm{CpG}$ dinucleotide and the mechanisms that guide methylation to specific sequences are unknown. The Dnmt1, Dnmt2, and Dnmt3 families diverged prior to the separation of the plant and animal kingdoms and are as distantly related to each other as they are to bacterial restriction methyltransferases that produce 5-methylcytosine $\left(\mathrm{m}^{5} \mathrm{C}\right)$. A brief introduction to the mammalian DNA methyltransferase families follows. 


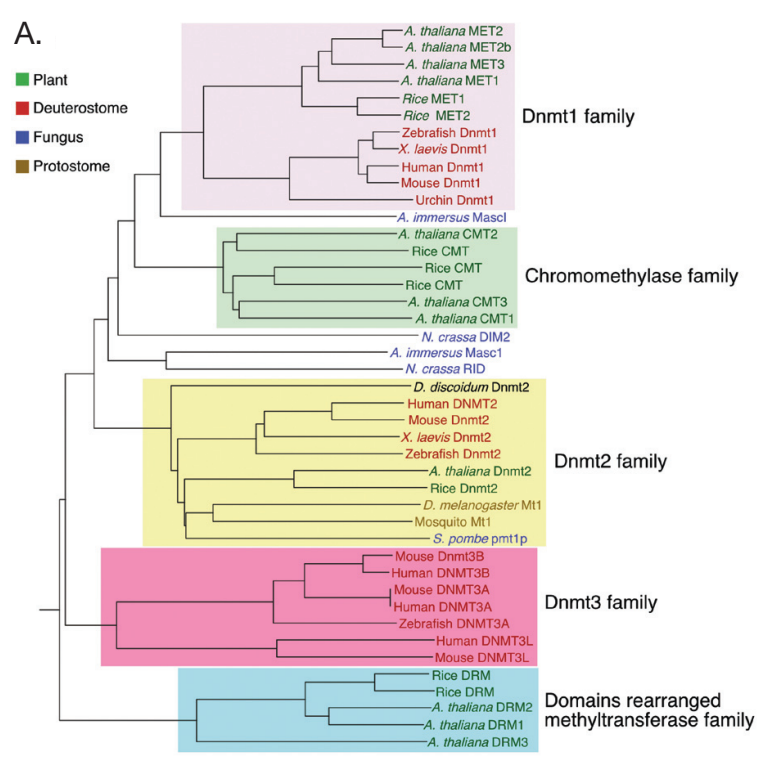

B.

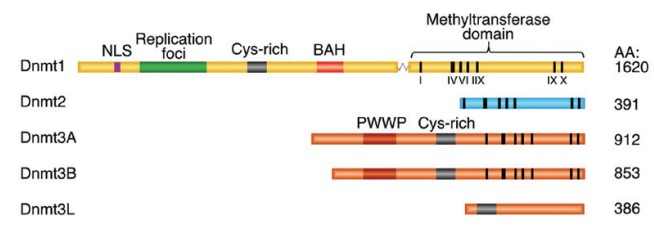

Figure 1. Sequence relationships among the catalytic domains of eukaryotic DNA cytosine methyltransferase. (A) ClustalW analysis of relationship of DNA methyltransferases from plants, deuterostomes, fungi, and protostomes. Note that the mammalian Dnmt1, Dnmt2, and Dnmt3 families all have homologs in plants. The most widely distributed DNA methyltransferase homolog is Dnmt2, whose function is unknown. Note deep branching of Dnmt3L from Dnmt3 branch. $(B)$ Domain and motif organization within the mammalian DNA methyltransferase homologs. Dnmt3L lacks the Dnmt signature motifs that mediate methyl transfer (dark vertical bars marked with Roman numerals for Dnmt1) but is clearly related to Dnmt3A and Dnmt3B in framework regions.

\section{Dnmt1}

The first mammalian DNA methyltransferase to be identified was cloned by chromatographic purification of the protein to homogeneity, determination of the sequence of cyanogen bromide peptides by vapor phase Edman degradation, and the preparation of degenerate oligonucleotide probes corresponding to the peptide sequences (Bestor et al. 1988). The enzyme cloned in this way was named DNA methyltransferase 1 (Dnmt1). Dnmt 1 contains a carboxy-terminal domain of about 500 amino acids that is closely related to bacterial cytosine- 5 restriction methyltransferases and a large $(\sim 1000$ amino acid) amino-terminal domain that has multiple regulatory functions, which include coordination of DNA replication and maintenance methylation, import of Dnmt1 protein into nuclei (Leonhardt et al. 1992), suppression of de novo methylation (Bestor 1992), and regulation of cellcycle-dependent protein degradation (Ding and Chaillet 2002).
The Dnmtl gene was disrupted by means of homologous recombination in embryonic stem (ES) cells (Li et al. 1992). Dnmt1-deficient mouse embryos had severely demethylated genomes and died at the headfold stage, while mutant ES cells grew normally but died when induced to differentiate in vitro or in vivo ( $\mathrm{Li}$ et al. 1992). The lethal differentiation phenotype is unique to the Dnmt1-deficient genotype. Further work showed that Dnmt1-deficient mouse embryos lost monoallelic expression at most imprinted loci (Li et al. 1993) and showed inactivation of all $\mathrm{X}$ chromosomes as a result of Xist reactivation (Panning and Jaenisch 1996). It was also shown that retroposons of the intracisternal A particle (IAP) class were transcribed at very high levels in Dnmt1 mutants; controls showed little or no expression (Walsh et al. 1998). Loss of methylation also destabilized the genome (Chen et al. 1998). These findings confirmed the essential role of genomic methylation patterns in mammalian development, something that had been in doubt because of the lack of cytosine methylation in popular model organisms such as Drosophila melanogaster and Caenorhabditis elegans. Cytosine methylation is now known to have essential roles in genomic imprinting, $\mathrm{X}$-chromosome inactivation, host defense against transposons, and genome stability (for review, see Bestor 2003). Incipient developmental abnormalities and ectopic or precocious activation of tissue-specific genes have not been seen in embryos with demethylated genomes; these and other lines of evidence are incompatible with the well-accepted (but hardly well-established) view that changes in methylation patterns regulate gene expression during development (Walsh and Bestor 1999).

Dnmt1 has been assigned the role of maintenance methyltransferase (that is, able to methylate only the hemimethylated DNA produced by semiconservative DNA replication) in order to satisfy predictions of distinct maintenance and de novo methyltransferases published almost 30 years ago (Holliday and Pugh 1975; Riggs 1975). However, Dnmt1 is more abundant and has a much higher specific activity on unmethylated DNA than does any other mammalian DNA methyltransferase (Yoder et al. 1997). Groudine and colleagues have shown that cells that lack both Dnmt3A and Dnmt3B (which have been held to be the sole de novo DNA methyltransferases [Okano et al. 1999]) remain capable of de novo methylation under certain conditions (Lorincz et al. 2002). While there is evidence that Dnmt1 is predominantly a maintenance DNA methyltransferase and is dispensable for imprint establishment in oogenesis (Howell et al. 2001), the exact functions of Dnmt1 cannot be delimited from the available data and a role in de novo methylation remains possible.

\section{Dnmt2}

Dnmt2 was the first DNA methyltransferase homolog to be identified by searches of EST libraries (Yoder and Bestor 1998). Dnmt2 has all ten of the sequence motifs usually diagnostic of DNA cytosine- 5 methyltransferases of both prokaryotes and eukaryotes, although the variable 
amino-terminal extensions that characterize the mammalian enzymes are absent from Dnmt2. Crystallographic studies have shown that every catalytic side chain is in the correct conformation to mediate the transmethylation reaction (Dong et al. 2001), but the protein has not displayed the expected activity in biochemical tests (Yoder and Bestor 1998; Dong et al. 2001) and ES cells and mice that lack Dnmt2 are viable and have no discernible defects in genomic methylation patterns or other discernible phenotypes (Okano et al. 1998; M.G. Goll and T.H. Bestor, unpubl.). Where Dnmt2 homologs are found they are very well conserved, and the phylogenetic distribution of Dnmt 2 is the widest but most variable of any DNA cytosine-5 methyltransferase homolog: It is present in the fission yeast Schizosaccharomyces pombe (but not in Saccharomyces cerevisiae or any other fungus whose genome has been sequenced) and in D. melanogaster and other insects but not in C. elegans. It is found in all protozoa, vertebrates, and plants (including diatoms, ferns, and mosses) tested to date and is present in two species of one prokaryotic genus (the sulfur-reducing genus Geobacter). We and our collaborators have constructed strains of $S$. pombe, D. melanogaster, A. thaliana, and mice that lack Dnmt2. None have shown any detectable phenotype after generations of propagation in the homozygous state. Dnmt2 is the only DNA methyltransferase homolog dispensable for survival under laboratory conditions. The biological function of Dnmt2 remains enigmatic.

\section{Dnmt3A AND Dnmt3B}

Dnmt1 and Dnmt2 are singleton proteins in mammals, but the Dnmt3 family contains three members, Dnmt3A, Dnmt3B, and Dnmt3L. Dnmt3A and Dnmt3B are closely related and have low but approximately equivalent enzymatic activities on unmethylated and hemimethylated substrates; they have been referred to as the "long sought" de novo DNA methyltransferases (Okano et al. 1998), again to satisfy predictions of 1975 (Holliday and Pugh 1975; Riggs 1975). Deletion of Dnmt3A does not cause detectable alteration of genomic methylation patterns in somatic cells of homozygous mice, although mutant male mice lack germ cells and both sexes die of a condition similar to aganglionic megacolon (Okano et al. 1999). Mice that lack Dnmt3B die as embryos with demethylation of minor satellite DNA but normally methylated euchromatic DNA; the Dnmt3A-Dnmt3B double mutant dies very early with demethylation of all genomic sequences in a manner similar to that of Dnmt1 null mutants (Okano et al. 1999). We showed that the rare human genetic disorder ICF syndrome (immunodeficiency, centromere instability, and facial anomalies) is due to recessive loss of function mutations in the DNMT3B gene (Xu et al. 1999). Patients with ICF syndrome fail to methylate classical satellite (also known as satellite 2 and 3 ) sequences on the juxtacentromeric long arms of chromosomes 1,9, and 16; these demethylated chromosomes gain and lose long arms at a very high rate to produce the multiradiate pinwheel chromosomes unique to this disorder.
Dnmt3A and Dnmt3B are clearly required for the establishment of genomic methylation patterns, but neither enzyme has inherent sequence specificity. The factors that designate specific sequences for de novo methylation are not known. Perhaps the outstanding problem in the mammalian DNA methylation field is the source of the sequence specificity for de novo methylation.

\section{FUNCTIONS OF Dnmt3L IN OOGENESIS}

As diagrammed in Figure 1B, Dnmt3L lacks the conserved motifs that mediate transmethylation but is related to Dnmt3A and Dnmt3B in framework regions (Aapola et al. 2000). Dnmt3L also fails to methylate DNA in biochemical tests. As shown in the diagram of Figure 2, expression of full-length Dnmt3L mRNA is confined to germ cells. (Sterile transcripts that initiate at a promoter located between exons 9 and 10 are expressed in spermatids. These truncated transcripts account for the large number of SAGE and EST hits in somatic cells [T. Shovlin et al., unpubl.].) Dnmt3L was of special interest because it is the only DNA methyltransferase homolog whose expression is confined to germ cells (Bourc'his et al. 2001). Disruption of the Dnmt3L gene by gene targeting in ES cells and insertion of a promoterless $\beta$-geo marker into the locus showed that Dnmt3L is expressed in growing oocytes (Bourc'his et al. 2004), the stage at which maternal genomic imprints are established (Kono et al. 1996). Mice homozygous for the disrupted Dnmt3L gene were viable and without overt phenotype, although both sexes were sterile. Males were azoospermic (the origin of this defect will be described in the following section), but oogenesis and early development of heterozygous embryos derived from homozygous oocytes was normal; the lethal phenotype was only manifested at e9. Such embryos showed signs of nutritional deprivation, and further analysis revealed a failure of chorioallantoic fusion and other dysmorphia of extraembryonic structures (Bourc'his et al. 2001). Analysis of expression of imprinted genes showed a complete lack of imprinting at maternally silenced loci and a lack of methylation of maternally methylated differentially methylated regions (DMRs). Bisulfite genomic sequencing showed that the imprinting defect was due to a failure to establish genomic imprints in the oocyte, and the normal imprinting of paternally silenced genes in heterozygous offspring of homozygous Dnmt3L-deficient females showed that imprint maintenance in the embryo was normal (Bourc'his et al. 2001). This contrasted with the situation in mice that lack Dnmt1o (an oocyte-specific isoform of Dnmt1) in which imprint establishment was normal but maintenance in preimplantation embryos was deficient (Howell et al. 2001). Methylation of sequences other than imprinted regions was normal in heterozygous embryos derived from homozygous Dnmt3L mutant oocytes (Bourc'his et al. 2001).

Dnmt3L behaves as a maternal-effect factor that is required only for imprint establishment in oocytes; as will described in the next section, the functions of Dnmt3L in male germ cells are completely different. 


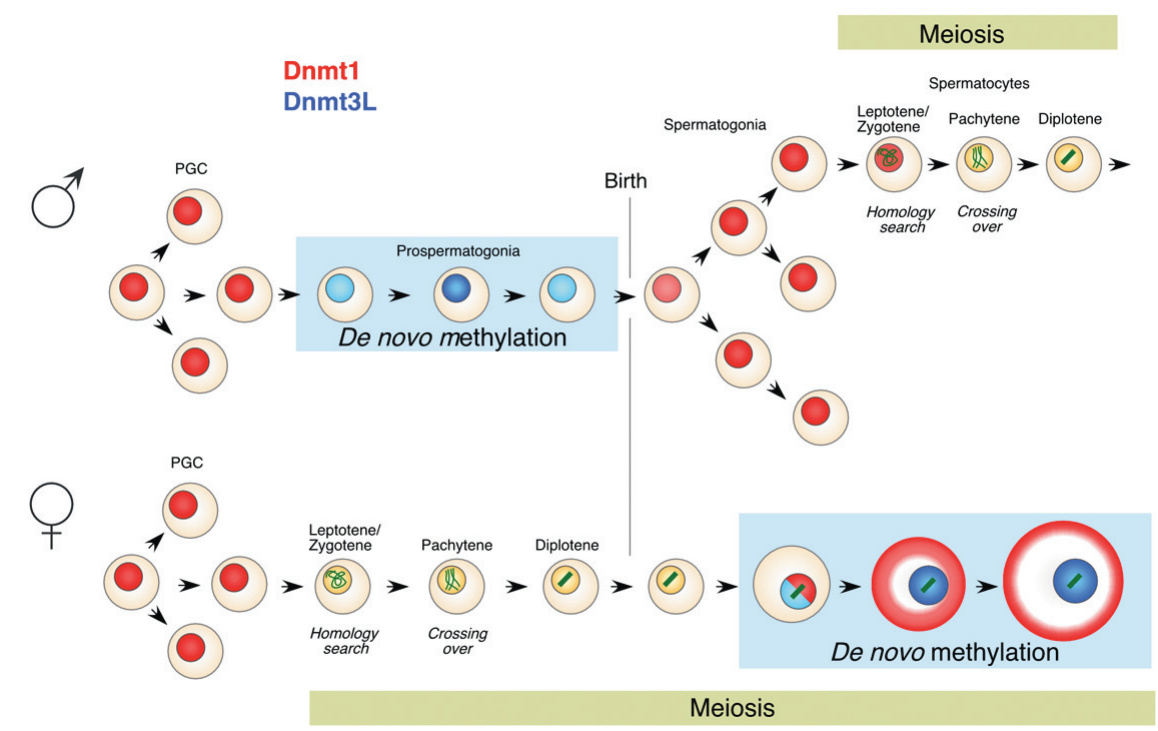

Figure 2. Expression of Dnmt3L and Dnmt1 in male and female germ cells. Intensity of blue coloration indicates relative levels of Dnmt3L; red indicates levels of Dnmt1. Dnmt3L is expressed in premeiotic male germ cells but only in growing oocytes in females. The full-length somatic form of Dnmt1 is expressed in proliferating primordial germ cells in both sexes and in proliferating spermatogonia in males; the truncated but active Dnmtlo isoform accumulates to very high levels in the cytoplasm of growing oocytes and is required for imprint maintenance specifically at the eight-cell stage (Howell et al. 2001). Dnmt3L is present only at the stages where genomic imprints are established and where transposons undergo de novo DNA methylation. (Data from Mertineit et al. 1998; Bourc'his et al. 2001; and La Salle et al. 2004.)

\section{FUNCTIONS OF Dnmt3L IN SPERMATOGENESIS}

In male mice Dnmt3L is expressed at significant levels only in perinatal prospermatogonia, the stage at which paternal genomic imprints are established (Davis et al. 1999) and transposons undergo de novo methylation (Walsh et al. 1998). Male mice that lack Dnmt3L are outwardly normal except for hypogonadism as adults (Bourc'his et al. 2001). The germ cell population is normal at birth, but only the first cohort of germ cells begins meiosis, and none reach the pachytene stage. All meiotic cells show extreme abnormalities of synapsis; grossly abnormal concentrations of synaptonemal complex proteins and nonhomologous synapsis (Fig. 3) are obvious in nearly all leptotene and zygotene spermatocytes. Adult males are devoid of all germ cells. This is in striking contrast to Dnmt3L-deficient females, where oogenesis is outwardly normal and a phenotype is only apparent in heterozygous offspring of homozygous females (Bourc'his et al. 2001).

The fact that Dnmt3L-deficient male germ cells show a phenotype only after the stage at which Dnmt3L protein is no longer expressed suggested an epigenetic or gene silencing defect. Homozygous mutant male germ cells were purified by flow sorting after staining with an antibody against germ cell nuclear antigen (GCNA; Enders and May 1994; the kind gift of G.C. Enders) and inspected for abnormalities of genomic methylation patterns. There is global genome demethylation in mutant spermatogonia and early spermatocytes as shown by increased sensitivity to methylation-sensitive restriction endonucleases (Fig. 4) (Bourc'his and Bestor 2004).

Transposons contain the large majority of $\mathrm{m}^{5} \mathrm{C}$ present in the mammalian genome (Yoder et al. 1997), and demethylation of the major transposon classes (IAP elements and LINE-1 elements) was observed in Dnmt3Ldeficient male germ cells. However, there was little or no demethylation of major or minor satellite DNA when compared with controls. This indicates that the methylation of heterochromatic satellite DNA is controlled by mechanisms distinct from those that control the methylation of euchromatic sequences. Other data support this conclusion; mutations in the DNMT3B gene in humans cause demethylation only of classical satellite (which is analogous to mouse major satellite) in ICF syndrome patients (Xu et al. 1999), and the methylation status of ma-
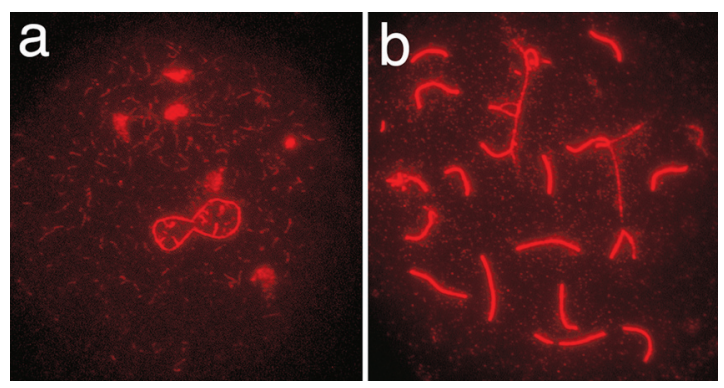

Figure 3. Meiotic catastrophe in spermatocytes derived from Dnmt3L-deficient prospermatogonia. (a) Formation of highly aberrant complexes of synaptonemal proteins in the form of interlocked rings and complex three-dimensional structures in spermatocytes that had lacked Dnmt3L in the earlier prospermatogonial stage. (b) Branching and anastomosing synaptonemal complexes in Dnmt3L-deficient spermatocytes. Many chromosomes are unpaired or engaged in nonhomologous synapsis; such nonhomologous pairing is not seen in control specimens. Similar staining patterns were seen after labeling with antibodies to Scp3 or combination of Scp1 and Scp3 antibodies. 


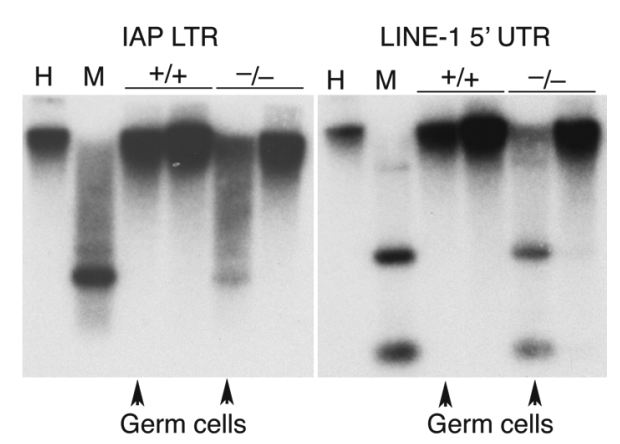

Figure 4. Transposon demethylation in Dnmt3L-deficient male germ cells. Germ cells from $17 \mathrm{dpp}$ testes were purified by fluorescence activated cell sorting after staining for GCNA1 (Enders and May 1994). DNA was digested with the methylation-sensitive restriction endonuclease HpaII prior to DNA blot analysis with the indicated probes, except in lanes headed M, which contained DNA that had been cleaved with MspI, a methylation-insensitive isoschizomer of HpaII. Full methylation of IAP LTR and LINE-1 5' UTR is visible in the wild-type lanes; note substantial demethylation in Dnmt3L-deficient male germ cells. (Arrowheads) Wild type (left in each blot) and Dnmt $3 \mathrm{~L}^{-1-}$ (right in each blot).

jor satellite (but not of other sequences) is affected by loss of the histone methyltransferases Suv39h1 and Suv39h2 (Lehnertz et al. 2003).

The host defense hypothesis predicts that demethylation of transposons will cause their transcriptional activation (Yoder et al. 1997; Bestor 2003). As shown in Figure 5 , there is massive reactivation of LINE-1 and IAP transcripts observed by in situ hybridization. Dnmt3L is therefore the first gene shown to be required for the silencing of transposons in germ cells of any organism. It is notable that homozygous loss of function mutations in Dnmt1 causes reaction of IAP transcription in somatic cells (Walsh et al. 1998), but LINE-1 elements are not reactivated (Bourc'his and Bestor 2004). LINE-1 elements are believed to be the source of reverse transcriptase for most retroposons, and the coexpression of IAP elements and LINE-1 elements suggests that active transposition of multiple retroposon classes will occur in Dnmt3L-deficient germ cells.

Kaneda et al. (2004) reported complete demethylation of the H19 DMR in Dnmt3L-deficient male germ cells. Our analysis shows only partial (50\%) demethylation in a larger set of data (Fig. 6). The recovery of only a single sequence by Kaneda et al. suggests that they may have sequenced the PCR products arising from a single demethylated DNA molecule. Our bisulfite sequencing results, which show no evidence of clonality, indicate that that removal of Dnmt3L has a much smaller effect on the establishment of methylation imprints at the H19 DMR than was reported by Kaneda et al.

As shown in Figures 1 and 7, Dnmt3L is evolving at a much higher rate than any other mammalian DNA methyltransferase-related protein; mouse and human Dnmt3L proteins are $<60 \%$ identical, while Dnmt1, Dnmt2, Dnmt3A, and Dnmt3B are all $>80 \%$ identical. The rapid evolution of Dnmt3L is likely to reflect the in-

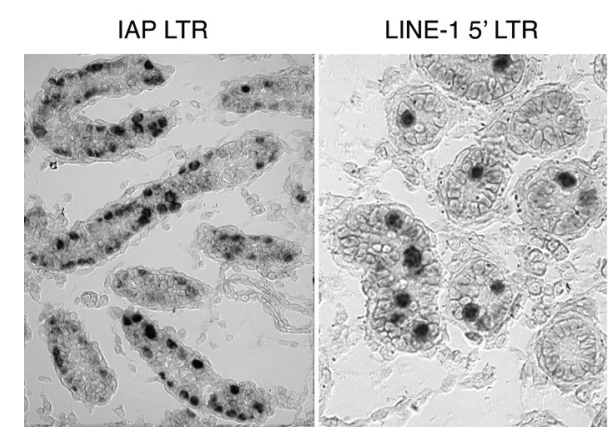

Figure 5. Transcriptional reactivation of retrotransposons in Dnmt3L-deficient germ cells. In situ hybridization against sections of testes from mice at $2 \mathrm{dpp}$ showed expression of high levels of LINE-1 and IAP transcripts in Dnmt3L-deficient prospermatogonia. Further analysis showed expression of LINE-1 and IAP transposons in dividing spermatogonia and spermatocytes as well.

volvement of the protein in transposon control. Host defense measures place transposons under selective pressure to evade these measures, which in turn pressures the host to evolve new countermeasures. This evolutionary chase is expected to manifest as rapid evolution of the regulatory factor in the host defense system; analysis of rates of sequence divergence indicate that Dnmt3L is under positive selection for rapid evolution and is likely to play a regulatory role, while the almost perfect conservation of mouse and human Dnmt3A suggests that this protein is under strong negative selection and has an essential catalytic function.

\section{SEXUAL DIMORPHISM IN GENOMIC IMPRINTING}

The sexual dimorphism in Dnmt3L phenotypes is striking and without precedent. The loss of Dnmt3L from male germ cells has a far smaller effect on imprint estab-

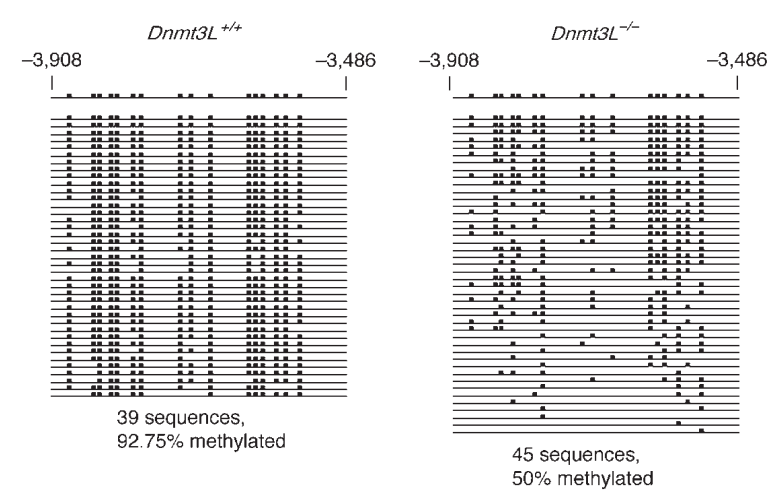

Figure 6. Partial imprint establishment at H19 in Dnmt3L-deficient male germ cells. Germ cells were isolated by flow sorting after staining with antibodies to GCNA1 (Enders and May 1994) and DNA subjected to methylation analysis by bisulfite genomic sequencing (Bourc'his et al. 2001). Establishment of imprints at H19 is only partially dependent on Dnmt3L 


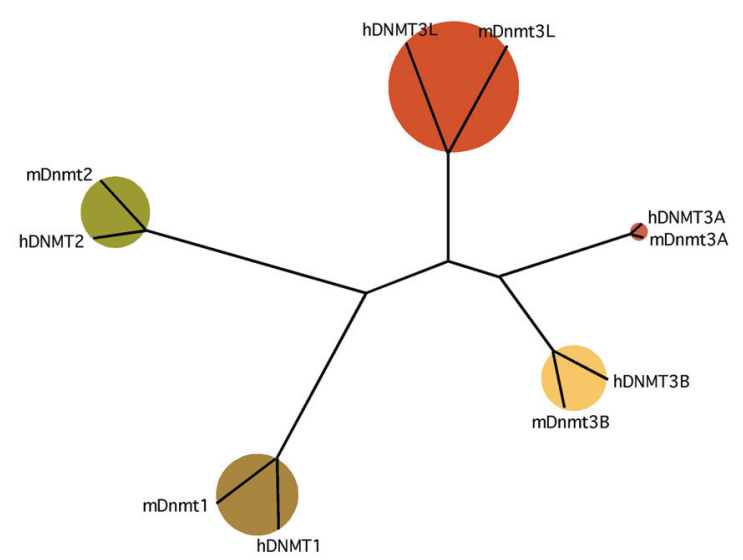

Figure 7. Rapid divergence of Dnmt3L protein sequence as compared to other mammalian DNA methyltransferase family members. ClustalW analysis of full-length sequences of mouse and human DNA methyltransferase-related sequences is shown. Dnmt3L can be seen to be diverging much more rapidly than other Dnmt pairs; sequence identity is $<60 \%$ for mouse and human Dnmt3L.

lishment than in female germ cells. Imprints at $H 19$ are only slightly reduced in Dnmt3L-deficient male germ cells, and there is no indication of activation of expression of the $H 19$ gene in these cells (Bourc'his and Bestor 2004). Dnmt3L is required for imprint establishment in female germ cells but not for normal meiosis or for global genome methylation, but in male germ cells is dispensable for imprint establishment but is required for meiosis and global genome methylation. Imprinting is therefore strongly dimorphic both in terms of the categories of genes that are imprinted in male and female germ cells (Reik and Walter 2001) and in the mechanisms that mediate promoter silencing in the two sexes (Bourc'his et al. 2001, and data shown here).

\section{DEDUCTION OF THE BIOLOGICAL EFFECT OF GENOMIC IMPRINTING FROM THE PHENOTYPE OF IMPRINT-FREE MOUSE EMBRYOS}

The nature of the biological function or functions of genomic imprinting has been controversial in part because phenotypic analysis has been restricted to animals that lack one or a few imprinted genes or that have only maternal or paternal imprints (Barton et al. 1984; McGrath and Solter 1984). The true nature of genomic imprinting could be revealed most clearly by analysis of development of mice that lack imprints altogether. This is now possible: Parthenogenetic activation of homozygous Dnmt3 $\mathrm{L}^{-}$oocytes with restoration of diploidy by inhibition of second polar body extrusion can be used to derive mouse embryos that lack both maternal and paternal imprints without global genome demethylation, as would occur if conditional alleles of Dnmt1 were to be employed. While there are recent indications that paternal imprints may be partially or completely dispensable for normal development under some conditions (Kono et al. 2004), it should be noted that the phenotypic differences between embryos derived by parthenogenetic activation of homozygous mutant Dnmt3L oocytes and fertilized Dnmt3L mutant oocytes will provide a direct measurement of the importance of and the biological effects of paternal imprints.

\section{ACKNOWLEDGMENTS}

Supported by grants from the National Institutes of Health and by a fellowship from the Rett Syndrome Research Foundation. We thank members of the laboratory for stimulating discussions.

\section{REFERENCES}

Aapola U., Kawasaki K., Scott H.S., Ollila J., Vihinen M., Heino M., Shintani A., Kawasaki K., Minoshima S., Krohn K., Antonarakis S.E., Shimizu N., Kudoh J., and Peterson P. 2000. Isolation and initial characterization of a novel zinc finger gene, DNMT3L, on 21q22.3, related to the cytosine-5methyltransferase 3 gene family. Genomics 65: 293 .

Barton S.C., Surani M.A., and Norris M.L. 1984. Role of paternal and maternal genomes in mouse development. Nature 311: 374 .

Bestor T.H. 1992. Activation of mammalian DNA methyltransferase by cleavage of a $\mathrm{Zn}$-binding regulatory domain. $E M B O$ J. 11: 2611.

. 2000. The DNA methyltransferases of mammals. Hum. Mol. Genet. 9: 2395

2003. Cytosine methylation mediates sexual conflict. Trends Genet. 19: 185.

Bestor T.H., Laudano A., Mattaliano R., and Ingram V. 1988. Cloning and sequencing of a cDNA encoding DNA methyltransferase of mouse cells. The carboxyl-terminal domain of the mammalian enzyme is related to bacterial restriction methyltransferases. J. Mol. Biol. 203: 971.

Bourc'his D. and Bestor T.H. 2004. Meiotic catastrophe and retrotransposon reactivation in male germ cells lacking Dnmt3L. Nature 431: 96.

Bourc'his D., Xu G.L., Lin C.S., Bollman B., and Bestor T.H. 2001. Dnmt3L and the establishment of maternal genomic imprints. Science 294: 2536.

Chen R.Z., Pettersson U., Beard C., Jackson-Grusby L., and Jaenisch R. 1998. DNA hypomethylation leads to elevated mutation rates. Nature 395: 89.

Davis T.L., Trasler J.M., Moss S.B., Yang G.J., and Bartolomei M.S. 1999. Acquisition of the H19 methylation imprint occurs differentially on the parental alleles during spermatogenesis. Genomics 58: 18-28.

Ding F. and Chaillet J.R. 2002. In vivo stabilization of the Dnmt1 (cytosine-5)- methyltransferase protein. Proc. Natl. Acad. Sci. 99: 14861 .

Dong A., Yoder J.A., Zhang X., Zhou L., Bestor T.H., and Cheng X. 2001. Structure of human DNMT2, an enigmatic DNA methyltransferase homologue that displays denaturantresistant binding to DNA. Nucleic Acids Res. 29: 439.

Enders G.C. and May J.J., II. 1994. Developmentally regulated expression of a mouse germ cell nuclear antigen examined from embryonic day 11 to adult in male and female mice. Dev. Biol. 163: 331 .

Goll M.G. and Bestor T.H. 2002. Histone modification and replacement in chromatin activation. Genes Dev. 16: 1739.

Henikoff S., Furuyama T., and Ahmad K. 2004. Histone variants, nucleosome assembly and epigenetic inheritance. Trends Genet. 7: 320.

Holliday R. and Pugh J.E. 1975. DNA modification mechanisms and gene activity during development. Science 187: 226. 
Howell C.Y., Bestor T.H., Ding F., Latham K.E., Mertineit C., Trasler J.M., and Chaillet J.R. 2001. Genomic imprinting disrupted by a maternal-effect mutation in the Dnmt1 gene. Cell 104: 829.

Kaneda M., Okano M., Hata K., Sado T., Tsujimoto N., Li E., and Sasaki H. 2004. Essential role for de novo DNA methyltransferase $3 \mathrm{a}$ in paternal and maternal imprinting. Nature 429: 900 .

Kono T., Obata Y., Yoshimzu T., Nakahara T., and Carroll J. 1996. Epigenetic modifications during oocyte growth correlates with extended parthenogenetic development in the mouse. Nat. Genet. 13: 91.

Kono T., Obata Y., Wu Q., Niwa K., Ono Y., Yamamoto Y., Park E.S., Seo J.S., and Ogawa H. 2004. Birth of parthenogenetic mice that can develop to adulthood. Nature 428: 860 .

La Salle S., Mertineit C., Taketo T., Moens P.B., Bestor T.H., and Trasler J.M. 2004. Windows for sex-specific methylation marked by DNA methyltransferase expression profiles in mouse germ cells. Dev. Biol. 268: 403.

Lehnertz B., Ueda Y., Derijck A.A., Braunschweig U., PerezBurgos L., Kubicek S., Chen T., Li E., Jenuwein T., and Peters A.H. 2003. Suv39h-mediated histone H3 lysine 9 methylation directs DNA methylation to major satellite repeats at pericentric heterochromatin. Curr. Biol. 13: 1192.

Leonhardt H., Page A.W., Weier H.-U., and Bestor T.H. 1992. A targeting sequence directs DNA methyltransferase to sites of DNA replication in mammalian nuclei. Cell 71: 865.

Li E., Beard C., and Jaenisch R. 1993. Role for DNA methylation in genomic imprinting. Nature 366: 362.

Li E., Bestor T.H., and Jaenisch R. 1992. Targeted mutation of the DNA methyltransferase gene results in embryonic lethality. Cell 69: 915.

Lorincz M.C., Schubeler D., Hutchinson S.R., Dickerson D.R., and Groudine M. 2002. DNA methylation density influences the stability of an epigenetic imprint and Dnmt3a/b-independent de novo methylation. Mol. Cell. Biol. 22: 7572.
McGrath J. and Solter D. 1984. Completion of mouse embryogenesis requires both the maternal and paternal genomes. Cell 37: 179.

Mertineit C., Yoder J.A., Taketo T., Laird D.W., Trasler J.M., and Bestor T.H. 1998. Sex-specific exons control DNA methyltransferase in mammalian germ cells. Development 125: 889 .

Okano M., Xie S., and Li E. 1998. Dnmt2 is not required for de novo and maintenance methylation of viral DNA in embryonic stem cells. Nucleic Acids Res. 26: 2536.

Okano M., Bell D.W., Haber D.A., and Li E. 1999. DNA methyltransferases Dnmt3a and Dnmt3b are essential for de novo methylation and mammalian development. Cell 99: 247.

Panning B. and Jaenisch R. 1996. DNA hypomethylation can activate Xist expression and silence X-linked genes. Genes Dev. 15: 1991

Reik W. and Walter J. 2001. Genomic imprinting: Parental influence on the genome. Nat. Rev. Genet. 2: 21.

Riggs A.D. 1975. X inactivation, differentiation, and DNA methylation. Cytogenet. Cell Genet. 14: 9.

Walsh C.P. and Bestor T.H. 1999. Cytosine methylation and mammalian development. Genes Dev. 13: 26.

Walsh C.P., Chaillet J.R., and Bestor T.H. 1998. Transcription of IAP endogenous retroviruses is constrained by cytosine methylation. Nat. Genet. 20: 116.

Xu G.-L., Bestor T.H., Bourc'his D., Hsieh C.-L., Tommerup N., Bugge G., Hulten M., Qu X., Russo J.J., and ViegasPéquignot E. 1999. Chromosome instability and immunodeficiency syndrome caused by mutations in a DNA methyltransferase gene. Nature 402: 187.

Yoder J.A. and Bestor T.H. 1998. A candidate mammalian DNA methyltransferase related to pmtlp of fission yeast. Hum. Mol. Genet. 7: 279.

Yoder J.A., Walsh C.P., and Bestor T.H. 1997. Cytosine methylation and the ecology of intragenomic parasites. Trends Genet. 13: 335. 


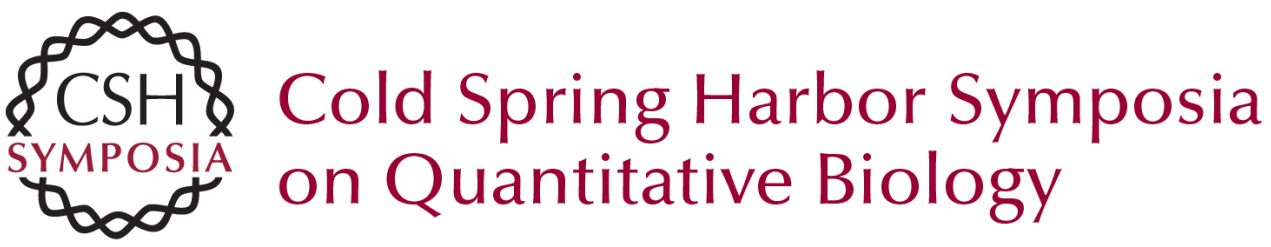

\section{Transposon Silencing and Imprint Establishment in Mammalian Germ Cells}

T.H. BESTOR and D. BOURC'HIS

Cold Spring Harb Symp Quant Biol 2004 69: 381-388

Access the most recent version at doi:10.1101/sqb.2004.69.381

References This article cites 38 articles, 7 of which can be accessed free at: http://symposium.cshlp.org/content/69/381.full.html\#ref-list-1

License

Email Alerting Receive free email alerts when new articles cite this article - sign up in Service the box at the top right corner of the article or click here. 